\title{
Contribution of the multi-attribute value theory to conflict resolution in groundwater management - application to the Mancha Oriental groundwater system, Spain
}

\author{
B. Apperl ${ }^{1, *}$, M. Pulido-Velazquez ${ }^{1}$, J. Andreu ${ }^{1}$, and T. P. Karjalainen ${ }^{2}$ \\ ${ }^{1}$ Research Institute of Water and Environmental Engineering (IIAMA), Universitat Politècnica de València, Camino de Vera \\ s/n, 46022 Valencia, Spain \\ ${ }^{2}$ Thule Institute, University of Oulu, P.O. Box 7300, University of Oulu, 90014 Oulu, Finland \\ *now at: Institute of Water Management, Hydrology and Hydraulic Engineering, University of Natural Resources and Life \\ Sciences, Muthgasse 18, Vienna, Austria
}

Correspondence to: M. Pulido-Velazquez (mapuve@upv.es)

Received: 29 June 2014 - Published in Hydrol. Earth Syst. Sci. Discuss.: 12 September 2014

Revised: - - Accepted: 17 February 2015 - Published: 9 March 2015

\begin{abstract}
The implementation of the EU Water Framework Directive demands participatory water resource management approaches. Decision making in groundwater quantity and quality management is complex because of the existence of many independent actors, heterogeneous stakeholder interests, multiple objectives, different potential policies, and uncertain outcomes. Conflicting stakeholder interests have often been identified as an impediment to the realisation and success of water regulations and policies. The management of complex groundwater systems requires the clarification of stakeholders' positions (identifying stakeholder preferences and values), improving transparency with respect to outcomes of alternatives, and moving the discussion from the selection of alternatives towards the definition of fundamental objectives (value-thinking approach), which facilitates negotiation. The aims of the study are to analyse the potential of the multi-attribute value theory for conflict resolution in groundwater management and to evaluate the benefit of stakeholder incorporation into the different stages of the planning process, to find an overall satisfying solution for groundwater management. The research was conducted in the Mancha Oriental groundwater system (Spain), subject to intensive use of groundwater for irrigation. A complex set of objectives and attributes was defined, and the management alternatives were created by a combination of different fundamental actions, considering different implementation stages and future changes in water resource avail-
\end{abstract}

ability. Interviews were conducted with representative stakeholder groups using an interactive platform, showing simultaneously the consequences of changes in preferences to the alternative ranking. Results show that the approval of alternatives depends strongly on the combination of measures and the implementation stages. Uncertainties in the results were notable, but did not influence the alternative ranking heavily. The expected reduction in future groundwater resources by climate change increases the conflict potential. The implementation of the method in a very complex case study, with many conflicting objectives and alternatives and uncertain outcomes, including future scenarios under water limiting conditions, illustrates the potential of the method for supporting management decisions.

\section{Introduction}

Groundwater is a vital natural resource for the reliable and economic provision of potable water supply in both urban and rural environments (Foster et al., 2002). It serves as a basis for life and social prosperity. The limited availability of clean water, whether it originates from rivers or from aquifers, produces conflicts. Groundwater resources in La Mancha Oriental are suffering increasing pressure due to water abstraction for irrigation and urban water supply (López Sanz, 2010). Conflicts related to large-scale ground- 
water management develop in many cases into intractable conflicts, which are typically very complex, involving many parties and interests, a long history, and even strong emotions (e.g. Llamas and Martinez Santos, 2005; Bromley et al., 2001).

To undertake a comprehensive decision-making approach, the complexity of groundwater management demands needs to represent all stakeholder interests, while being understandable for stakeholders in a participative context (Karjalainen et al., 2013). The guarantee of a balanced use of the available water is attempted by legislative restrictions, but also by increasing the awareness and participation of society (LópezGunn and Martinez-Cortina, 2006). With the implementation of the European Water Framework Directive, WFD (European Commission, 2000), the ecological function of water becomes more relevant for decision making. To guarantee the fulfilment of the WFD while maximising social benefits, effective management of the available resources is required. The WFD requires that member states take the necessary measures to "protect, enhance and restore all bodies of groundwater". The objective for groundwater bodies is to reach a "good" groundwater status, which implies both a good quantitative and good chemical status. The directive requires the definition and implementation of cost-effective combinations of measures that should be implemented to achieve good groundwater status. The high complexity and uncertainty demands decision support tools that help the decision makers to find an optimal solution by assessing the trade-offs among economic, social and ecological objectives.

The use of multi-criteria decision analysis (MCDA) can help facilitate the negotiation process among stakeholders by changing their preferences towards more consensusorientated decisions (Hostmann et al., 2005; Marttunen et al., 2013). A comprehensive approach is required to face the multiple objectives and alternatives (Karjalainen et al., 2013; Stefanopoulos et al., 2014). As MCDAs are often technically oriented, complex and difficult to understand for laymen (Kangas et al., 2008), the challenge exists in finding an evaluation process of alternatives that are comprehensible for stakeholders while representing the complexity of environmental decision processes.

Decision-making methods share common characteristics, such as the presence of multiple, non-commensurable and conflicting criteria, different units of measurement among the criteria and the presence of quite different alternative policies (Bogardi and Nachtnebel, 1994). This work analyses the different management alternatives by focusing first on the objectives (value-thinking approach) and, secondly, on evaluating the alternatives using the multi-attribute value theory (MAVT). The MAVT represents a value measurement model in which numerical scores are constructed in order to represent the degree to which one decision option may be preferred over another (Keeney and Raiffa, 1976). The approach has been proven to provide a transparent and systematic framework to analyse problems with multiple criteria and alternatives when working with stakeholders (Mustajoki et al., 2011; Karjalainen et al., 2013).

The main objective of this work is to test the aptitude of MAVT in analysing the complex system of groundwater management and to enhance conflict mediation in the Mancha Oriental (MO) aquifer in eastern Spain. In the MO aquifer, management conflict is a long lasting and complex problem in which collective actions play an essential role (López-Gunn, 2003).

This study applies the MAVT approach to facilitate conflict resolution for a sustainable management of the MO aquifer, and estimates the conflict potential for different management alternatives considering stakeholder preferences and values. The method considers all possible alternative policies, identifies different objectives and elicits stakeholder preferences on the objectives. Key questions of the analyses are the following.

- How do stakeholders rank management alternatives and are the results of our method coherent with holistic rankings?

- What are the principal points of conflict?

- How do different future scenarios influence the preferences of stakeholders?

- What are the advantages of stakeholder inclusion for sustainable groundwater management?

\section{Method}

The MAVT is a multi-criteria decision analysis (MCDA) tool for solving complex real-world decision problems, judging different amelioration alternatives for finding a well-accepted solution (Mustajoki et al., 2011; Bogardi and Nachtnebel, 1994). Different alternatives are ranked by evaluating the fulfilment of set objectives. Stakeholder interviews and workshops are used to elicit their preferences.

For the evaluation of the alternatives, we adopted the additive value function (weighted sum of a single attribute function) (Belton and Steward, 2002; Hostmann et al., 2005):

$V(A)=\sum w_{i} \cdot v_{i}\left(a_{i}\right)$,

with $a_{i}$ as the level of attribute $i$ resulting from alternative $A, v_{i}\left(a_{i}\right)$ the single attribute function, $w_{i}$ the weights of the attributes and $V(A)$ the total value of the alternative.

The value function has the vector of attribute levels that quantifies the effects of an alternative as an argument and converts it into a single value that expresses the satisfaction for that alternative in regard to an objective (Soncini-Sessa, 2007). The single value ranges from 0 to 1 for every objective and allows different objectives to be compared. The single value function is unique for every stakeholder and objective. The weights express the importance of each criterion compared to other criteria. The value of the weights depends on 


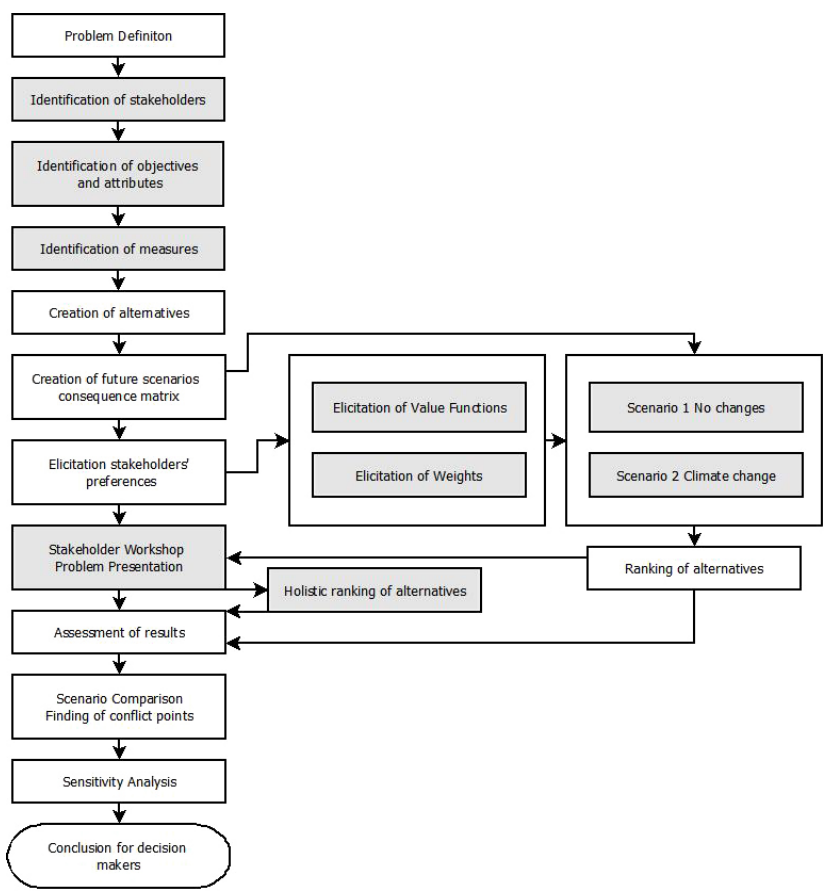

Figure 1. Method of evaluation of alternatives: grey charts indicate parts with stakeholder involvement.

the relative importance that the stakeholder associates with each attribute. The goal is to attain lumped measurement for the attractiveness or utility of the outcome of a set of alternatives by stakeholders.

\subsection{General approach}

The general approach of the evaluation process is shown in Fig. 1. The applied approach is almost similar to the DAI approach (the decision analysis approach; Marttunen and Hämäläinen, 1995; Karjalainen et al., 2013) that provides strong interactivity with the stakeholders through facilitated meetings and personal computer-aided interviews of stakeholders.

In a very first step, the problem has to be defined clearly. The second step involves a complete identification of the stakeholders who are involved in the problem. The snowball approach is used for that purpose. A crucial step (step 3) is the identification of all stakeholder objectives. Objectives are identified with stakeholders, representing their values and interests. They are ordered in a hierarchy tree with different levels of detail, considering the different scope, inconsistency and explicitness (Keeney and Raiffa, 1976). We arranged lower-level objectives into ecological, economic and social objectives (Bogardi et al., 1982). Afterwards (step 4), potential measures are defined and combined into alternatives (step 5).

The description of impacts is carried out through a consequence table (step 6) showing the consequence that a given

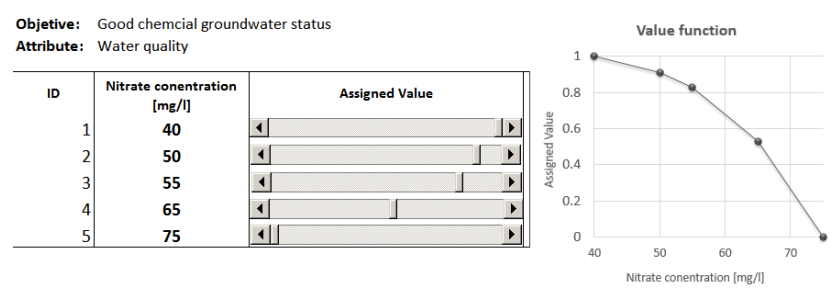

Figure 2. Interactive tool for stakeholders to define value functions (developed in Microsoft Excel).

alternative will have for a given objective. A consequence matrix is built up through various sub-steps (Keeney and Raiffa, 1976). First, the physical impact of an alternative to the hydrological system is analysed and quantified using measurable units. Then, its socioeconomic and economic impacts are quantified. To include the possible impacts of climate change on preferences, two impact matrices are created, where one depicts the status quo of available water resources and the other one includes changes in future water resource availability. In step 7, interviews are conducted to elicit stakeholders' preferences which are described in detail below. The results from steps 6 and 7 are combined with Eq. (1) to rank the alternatives (step 8) among the stakeholders. Afterwards, they are presented in a workshop (step 9), where stakeholders are also asked to rank the measures independently of any prior objectives. The results (8 and 9) are assessed and interpreted in step 10, and differences in rankings of future scenarios are compared (step 11). Finally, a sensitivity analysis is conducted to test the robustness of the obtained results towards uncertainties in the attribute levels of the alternatives (consequence matrix) and in the attribute valuation of the stakeholders.

\subsection{Stakeholders' preferences}

Stakeholders are asked in the interviews to evaluate different levels of attributes for every objective on a standardised scale. The attribute level range must cover all the attribute levels of the alternatives, limited by the highest and lowest levels of all of them (Keeney and Raiffa, 1976).

The single attribute value function $v_{i}\left(a_{i}\right)$ is assessed with the direct rating method, which is a numerical estimation method (von Winterfeldt and Edwards, 1986). The evaluation is done with Microsoft Excel ${ }^{\odot}$ on an interactive evaluation platform, so that the decider is able to see a visualisation of answers (Fig. 2). The range of attribute levels is limited by the highest and lowest levels of the attribute in all alternatives of both scenarios. The respondent is asked to estimate the strength of preferences of every attribute level on a numeric scale between 1 and 0 , with 1 as the most preferred level and 0 as the least preferred level. The remaining levels have to be rated between 1 and 0 , considering the space between two attribute levels as the strength of preference between them. 


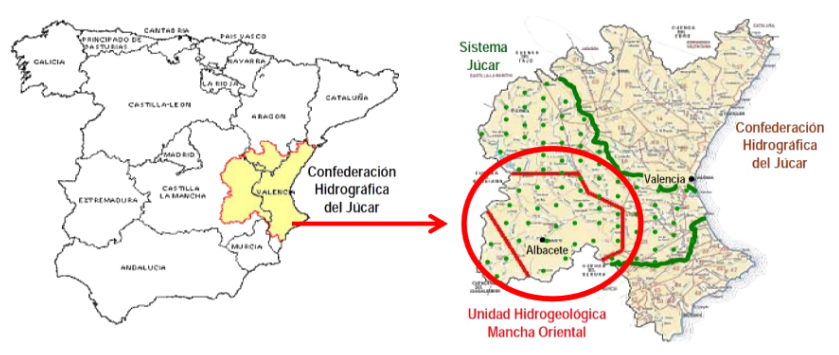

Figure 3. Case study area: Mancha Oriental aquifer in south-eastern Spain.

The value function is a transformation of the attribute levels of the objective on a comparable scale between 1 and 0 .

In addition to the value functions, the weights of the different objectives have to be elicited for every representative. To avoid the risk of stakeholder behavioural biases, it is of high importance to understand the possible influences and impacts on the results of different methods (Roberts and Goodwin, 2002). Different weighting methods lead to different results, although they are based on the same theoretical assumptions (Pöyhönen and Hämäläinen, 2001). Therefore, it is important to use a method which on the one hand, is easily understandable for the interviewed persons and on the other hand, statistically applicable and traceable. In this study, we have applied the SWING method (von Winterfeldt and Edwards, 1986). In this approach, the attribute ranges are explicitly incorporated into the elicitation questions, being proven to be a successful method in convergence tests (Pöyhönen and Hämäläinen, 2001).

The calculation of the results was realised with WebHIPRE $^{\circledR}$ version 1.22 , a web version of the HIPRE $3+$ software for decision analytic problem structuring, multi-criteria evaluation and prioritisation (Mustajoki and Hämäläinen, 2000). The further processing of the data was realised with Microsoft Excel ${ }^{\odot}$.

The preferences have been ranked and the different fundamental actions have been analysed. Additionally, a sensitivity analysis has been conducted to deal with uncertainty in the valuations and also with uncertainty in the attribute levels. The conflict potential has been interpreted and the ranking discrepancy expressed by the mean standard deviation of the average ranking of all stakeholders. The influence of the dynamic variables has been analysed by comparing the two scenarios, observing the changes in the rankings. Finally, the aptitude of the MAVT method has been evaluated, comparing the results of the model with the results of the holistic alternative ranking, which have been evaluated by some catch questions in the interviews.

\section{The case study}

\subsection{Description}

The Mancha Oriental (MO) aquifer is located in southeastern Spain in the eastern part of the Mancha plain, mainly in the provinces of Albacete and Cuenca, in the Castilla-La Mancha region (central Spain), with small areas in the Valencian Community and Murcia (see Fig. 3). It is part of the Júcar River basin district as one of its 52 groundwater bodies, with a total extension of approximately $8000 \mathrm{~km}^{2}$ (CHJ, 2009), and is consequently the biggest aquifer of this system and one of the largest carbonate aquifer systems in Spain. The major part of the system belongs to the catchment of the Júcar River, which is strongly connected to the aquifer.

The region is characterised by a semiarid continental climate, with an effective average rainfall of about $350 \mathrm{~mm}$ year $^{-1}$ varying between $150 \mathrm{~mm}$ in dry years and $750 \mathrm{~mm}$ in humid years (López-Fuster, 1999). The average net precipitation of the system from 1945 to 1975 was about $338 \mathrm{Mm}^{3}$ year $^{-1}$ (CHJ, 2009). However, in the last decade, it decreased to $292 \mathrm{Mm}^{3}(86 \%)$.

With its high agricultural activity and semiarid climate, about $90 \%$ of water in the eastern Mancha region is demanded by agriculture (CHJ, 2009), of which the major part is used for irrigation and a small part for livestock breeding. Urban water demand accounts only for about $10 \%$ of the total demand and plays a secondary role. The intensive expansion of irrigation since the early 1970s and the cultivation of high water consumption crops led to a significant increase in water demand and groundwater pumping. In the last years, the gross extractions have stabilised between 300 and $450 \mathrm{Mm}^{3}$. However, the renewable resources are assessed between 280 and $330 \mathrm{Mm}^{3}$ year $^{-1}$ (CHJ, 2009) and, consequently, the aquifer balance is still negative.

The intensive groundwater pumping has led to a significant drop in the groundwater level, and the piezometric level is locally about $35 \mathrm{~m}$ or more under the level of the natural regime (Sanz et al., 2009). As a consequence, the springs, whether they are permanent, temporal or ephemeral, are suffering a notable change in the discharge, and $13 \%$ of them have dried up (López-Sanz, 2010). Also, the discharge of the Júcar River is heavily influenced, as stream aquifer interaction in the upper reach has changed from a gaining river to a losing or even non-connected river.

The Júcar River is the main surface watercourse in the Mancha region. In the upstream limit of the aquifer region, the Alarcón reservoir (with a storage capacity of $1112 \mathrm{Mm}^{3}$ ) serves the main streamflow regulator, providing water supply for urban demand in the region and partially for agriculture. El Molinar reservoir represents the downstream geographic limit of the Júcar River reach within the MO region.

The MO aquifer system has suffered since the early 1970s from a continuous drop in groundwater levels due to intense groundwater pumping. This pumping has been provoked by 
an important transformation from dry land to irrigated land and consequently an increasing demand for irrigation water for agriculture. Promoted by economic incentives, the development of an intensive agriculture has led to a total irrigated area of about 100000 ha, whereof the predominant part is supplied by groundwater. Agriculture is the most important economic factor in the MO region. However, the overexploitation of the aquifer produces important ecological impacts, ranging from the drying of springs and wetlands to the disappearance and regime alteration of the rivers and the pollution of groundwater from nitrogen leaching due to the intense fertiliser use. Nitrate concentrations in groundwater of up to $125 \mathrm{mg} \mathrm{L}^{-1}$ have been measured at certain locations (Moratalla et al., 2009), and the aquifer has been designated a nitrate vulnerable zone by the Castilla-La Mancha regional government.

Yet, water use from the aquifer is limited by the River Basin Authority (Confederación Hídrográfica del Júcar) and the Jucar River Basin Management Plan. The regulation and control of water abstractions is managed by the Junta de Regantes de la Mancha Oriental, with about 800 members and an irrigated area of 90000 ha. Groundwater abstractions and water use are controlled by remote sensing and personal inspections (Castaño et al., 2010). The total irrigated area fluctuates between 100000 and 110000 ha.

Various measures have already been proposed to halt overexploitation and achieve the goal of sustainable aquifer management, by controlling the quantitative overexploitation of the aquifer through collective actions (López-Gunn, 2003) and achieving a good chemical status of the aquifer through the use of fertiliser standards and fertiliser taxes (Peña-Haro et al., 2010, 2014).

This study intends to identify the points of conflict between stakeholders to create a basis for further planning, and also to sensitise the stakeholders to possible impacts caused by different management. A general approach to find well-accepted measures should be found by testing the MAVT method, incorporating the stakeholders. And finally, the method's aptitude for conflict resolution in water management has been evaluated. The impact assessment of the measures and the evaluation of alternatives have been realised for the year 2027, which is homogeneous with the provided deadline of fulfilling the goals set in the WFD in the second instance. To evaluate the robustness to external changes, two future scenarios were considered: a static and a dynamic one, including possible changes in the available water resources in future. The application of the MAVT in the case study of the MO aquifer should give an idea of the possible impacts of various alternatives, its fulfilment of the objectives for the different stakeholders, and the conflict potential of the alternatives between the stakeholders. Furthermore, the aptitude of the MAVT as a tool for conflict resolution in water management has been tested.

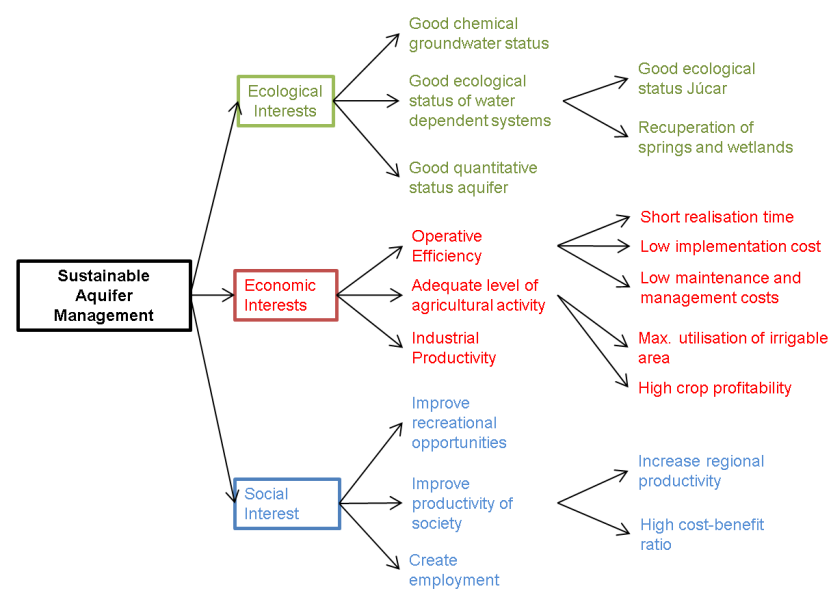

Figure 4. Hierarchy value tree of objectives from interviews with experts and stakeholders.

\subsection{Application}

\subsubsection{Identification of stakeholders}

The very first step was the characterisation of the problem of sustainable groundwater management in the case study and the identification of all the relevant stakeholders involved. In a large and complex groundwater system such as the MO, a broad range of interests are involved. The identification of the main stakeholders involved in this study was based on interviews with experts with regional knowledge and the application of the snowball principle, which involves asking already identified stakeholders to identify new ones (Hostmann, 2005). Eight stakeholder groups were finally selected (Table 1).

During the identification process, we checked whether a stakeholder's involvement was reasonable for avoiding biased results. Therefore, three exclusion criteria were defined:

- lack of knowledge about the aquifer system;

- lack of willingness to cooperate; and

- missing empathy with the aquifer management problem.

\subsubsection{Identification of objectives and attributes}

A hierarchy tree (see Fig. 4) was defined by experts and afterwards discussed and adapted with experts and stakeholders until the constructed hierarchy of objectives was accepted by all of them. This was absolutely crucial for gaining acceptance of the results. All the objectives contribute to the overall goal of sustainable management of the groundwater system.

Afterwards, attributes with measurable units were assigned to each objective on a quantitative or qualitative scale 
Table 1. Stakeholder groups and representatives in La Mancha Oriental.

\begin{tabular}{llr}
\hline Stakeholder & Representation & Interviewee(s) \\
\hline National administration & Jucar River Basin Authority & 1 \\
Regional administration & Regional government & 1 \\
Municipalities & Local government, municipal association & 2 \\
Agricultural representatives & Junta Central de Regantes de la Mancha Oriental & 1 \\
Environmental organisation & Local environmental organisations & 2 \\
Industry & Power generation, water-using industry, fertiliser production & 0 \\
Recreational organisations & Recreational and tourism organisations & 0 \\
Regional development organisations & ADIMAN, Institute of Regional Development & 2 \\
\hline
\end{tabular}

in order to assess the performance of the different alternatives in relation to that objective. A qualitative scale was assigned when a high uncertainty existed in the impact assessment, and also if the comprehensibility of qualitative data in the valuation process was easier for stakeholders. One of the criteria was that a clear association of the attribute with the objective be given (Keeney and Raiffa, 1976). Another criterion was the validity of the attribute in the entire study area, as the MO aquifer management issues are not only local. Physical impacts especially were expressed all over the area's representative value (e.g. groundwater depletion cannot be used as an attribute, as the impact varies over the area). A division of the objectives into geographical zones by lower-levelled subobjectives was contemplated, but finally rejected, because of the danger of the appearance of local interests in the valuation process and the loss of the objective character. A list of identified objectives with attributes can be found in Table 2 .

\subsection{Definition of management alternatives}

Management alternatives were not defined by experts, but were created from already proposed measures. Given that the overexploitation of the MO aquifer has been a problem for many years, different measures have already been developed by different organisations, varying in the basic approach to solving the aquifer management problem (LópezGunn, 2003; Martín de Santa Olalla Mañas et al., 1999; PeñaHaro et al., 2010, 2014). After all potential measures were identified, they were grouped into fundamental actions (FA).

1. FA1: Control/restriction of groundwater use

a. Reduction in irrigated agricultural area, change to dry farming

b. Reduction in water allotment in drought periods

c. Change of crops

d. Improvement in extraction controls

e. Improvement in irrigation efficiency

2. FA2: Increased surface water use / groundwater substitution a. Groundwater substitution by surface water for agricultural and urban water supply

3. FA3: Water demand reduction by economic instruments

a. Implementation of fertiliser standards

b. Implementation of water taxes and fertiliser taxes

To generate alternatives, a system-generating approach was applied, creating for every fundamental action different levels of implementation (Bogardi et al., 1982), from slow (level 1) to high (level 3).

FA1: (W1, W2, W3)

FA2: (S1, S2, S3)

FA3: (E1, E2, E3)

In a further step, the actions were combined with all different implementation stages considering various restrictions $(R)$. In total, 27 discrete alternatives $\left(A_{i}\right)$ were defined by

$A_{i}=A_{i}\left(W_{j}, S_{k}, E_{l} ; R\right)$.

The alternative with the lowest implementation stage for all fundamental actions represents the status quo alternative. The compatibility of the different measures was checked. Two exclusion criteria to check for compatibility have been set: (1) two measures are partially dependent and have contradictory outcomes, and (2) a measure makes another measure redundant. Restrictions $(R)$ referred to external or immutable variables that influence the available water resources. In the MO aquifer, these restrictions come from river discharge constraints for downstream adjacent regions, but also reliability of the urban water supply. Putting restrictions helped to focus on an inner solution of the aquifer management.

Although the direct ranking of a high number of complex alternatives with different outcomes would be a very difficult, unrealistic and probably meaningless task for the stakeholders, the MAVT will allow for the indirectly ranking of the alternatives for each stakeholder by obtaining their values and preferences in terms of objectives, and by assessing the performance of the alternatives on those objectives. 
Table 2. Attributes and measurement units for the lowest-level objectives.

\begin{tabular}{|c|c|c|}
\hline Objectives & Attribute & Unit \\
\hline Good chemical groundwater status & Water quality & $\begin{array}{l}\text { Groundwater nitrate } \\
\text { concentration: } \mathrm{mg} \mathrm{L}^{-1}\end{array}$ \\
\hline Good quantitative status of the aquifer & Groundwater budget & million $\mathrm{m}^{3}$ year ${ }^{-1}$ \\
\hline Recuperation of springs and wetlands & Recuperation potential & Qualitative scale \\
\hline Good ecological status (Júcar) & Stream-aquifer interaction & Qualitative scale \\
\hline Max. utilisation of irrigable areas & Irrigation area & ha \\
\hline High crop profitability & Net benefit per ha. & EUR \\
\hline Industrial productivity / energy potential & Influence on energy production in the Júcar River & Qualitative scale \\
\hline Short realisation time & Time between planning and realisation times & Years \\
\hline Low implementation costs & Cost of measures, etc. & EUR/qualitative \\
\hline Low maintenance and management cost & Cost of administration and control & EUR \\
\hline Create employment & Number of jobs & Number of jobs \\
\hline Improve recreational opportunities & Recreational space & Qualitative scale \\
\hline Increase in regional productivity & Influence on per capita income of region & $+/-$ \\
\hline High cost-benefit ratio & Cost-benefit ratio & $\%$ \\
\hline
\end{tabular}

\subsection{Impact assessment}

To assess how well each alternative meets the objectives, the impact assessment was forecasted for a certain time horizon. As the principal objectives are based on the guidelines of the WFD, the deadlines for its implementation were chosen. The date of evaluation was set in 2027, since this is one of the stages to be addressed. The base situation described the average situation between 2000 and 2008 to avoid possible anomalies of one specific year. Some of the proposed measures have already been implemented or are in the process of realisation.

To analyse the influence of climate change and other changes in the hydrological system, two scenarios with different assessment (consequence) matrices were introduced:

- scenario 1: static scenario; and

- scenario 2: dynamic scenario.

Scenario 1 assumes no changes in external influences or restrictions to the base situation between 2000 and 2008. This scenario focuses on the changes and influence of agricultural management measures.

Scenario 2 incorporated changes in urban water demand and climate. The possible impact of climate change on water resources (Chirivella-Osma, 2010) and the possible increase in urban water supply, handled as a restriction, were introduced into the calculation of the impact assessment. By comparing the results, the vulnerability of the acceptance of different measures and changes in preferences could be evaluated as well as the importance of the outcome by considering such variables.

For the assessment of the physical impact assessment, we used an existing groundwater model (Sahuquillo et al., 2008; Sanz et al., 2011), groundwater budgets from the annual statistics of the Jucar River Basin Agency (CHJ) and piezometric level observations (Lopez Sanz, 2010). Fitted regression equations (Sanz et al., 2009) and nitrate measurements (Moratalla et al., 2009) were used to estimate the influence of management options on nitrate concentration. For the assessment of possible climate change impacts on the water resources, we used estimations from Chirivella-Osma (2010) and Chirivella-Osma et al. (2015).

For the assessment of economic and socioeconomic impact, we used input-output matrices from the statistics institute of Castilla-La Mancha, and fitted regressions from previous hydroeconomic models of the groundwater system (Peña-Haro et al., 2010, 2014) to estimate the effects of different policies such as fertiliser taxation and water prices, and other relevant data from previous studies in the same case study (López Fuster, 1999; Martín de Santa Olalla Mañas, 1999)

\subsection{Quantification of the stakeholders' preferences}

The value function and the weights of the alternatives were elicited through interviews with representatives of every stakeholder group. The valuation of the attributes was realised for the range between the lowest and highest levels of the attribute for all alternatives in both scenarios. This range differed slightly between the two scenarios, and it would have required separate valuation interviews for every scenario. However, it was confusing for stakeholders to realise an interview twice with almost identical ranges of attributes. Because of this, a little error has been accepted, as it was not of high significance to the outcomes. Also, the use of qualitative scales of attribute levels reduced this problem.

Personal computer-aided interviews (Sect. 2.2) were conducted with representatives of the stakeholder groups. Either the interview was with the official spokesman of a stake- 


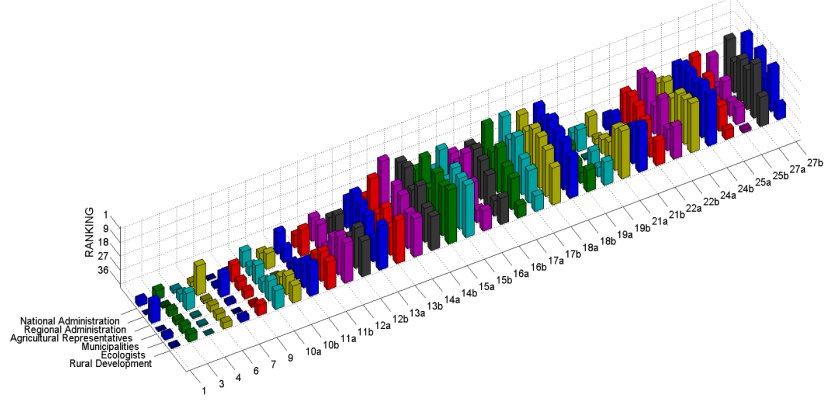

Figure 5. Ranking of alternatives by the stakeholders in scenario 1 .

holder group or with at least two stakeholders per stakeholder group, to maintain the objective character. Within one stakeholder group, the values of the representatives were averaged. If a stakeholder was not available for a personal interview, it was conducted by electronic interview, although personal interviews were preferred to avoid misinterpretations or errors in the valuation. In addition to the elicitation of the value function and weights, some general questions about the aquifer management were asked. Through the interview questions, the interviewee's holistic preferences were evaluated. Afterwards, a workshop in Albacete (Spain) was held, where the results were presented and stakeholders were asked to evaluate their prior valuation of preferences.

\section{Results}

\subsection{Ranking of alternatives and interpretation of results}

Based on the total value of the alternatives for the stakeholder groups, we proceeded to rank the different alternatives between 1 (best) and 36 (worst). The different alternatives were ranked quite similarly (see Fig. 5) across the stakeholder groups, although some clear discrepancies can also be detected. According to the results of the MAVT method, stakeholders tend to prefer a mix of different fundamental actions for problem resolution. The potential of combined measures might be preferred for economic reasons, and might cause smaller impacts distributed in various sectors instead of one rigorous measure. For an alternative to be considered good, ecological, economic and also social interests have to be considered. Of course, among the different stakeholder groups the focus differs, but the best-ranked alternatives are still the same. Figure 6 shows the evaluation of the alternatives and the range of variation between stakeholders. The best overall alternatives were chosen in two steps. Firstly, all dominated alternatives were eliminated. Secondly, the sum of the stakeholder rankings was calculated for every alternative. The lower the sum of ranking, the better the overall evaluation.

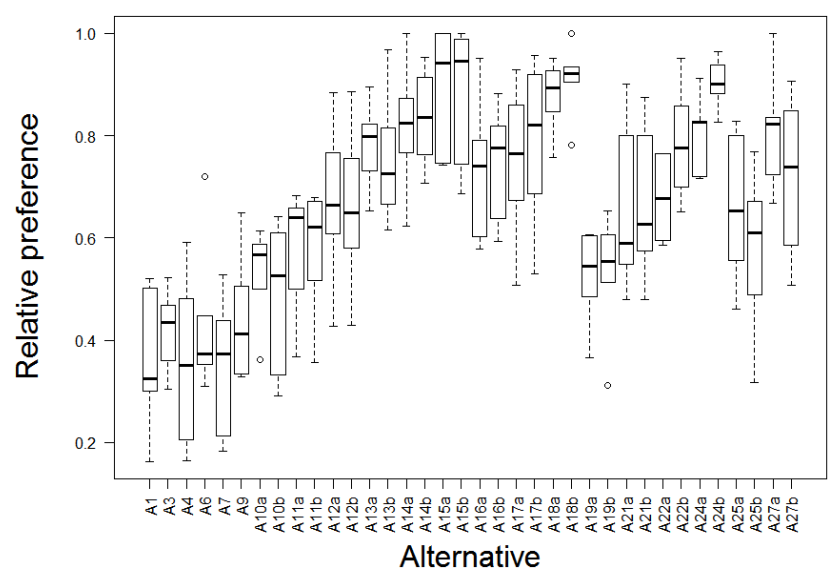

Figure 6. Standardised values of preferences of the alternatives by the stakeholders (min, median, 75th percentile, max).

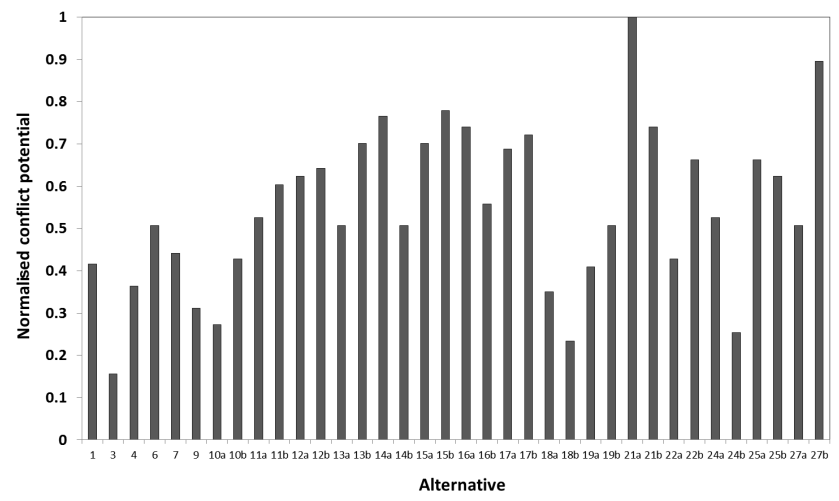

Figure 7. Normalised value ranking discrepancy expressed through the mean deviation of preference relative values across stakeholders.

By analysing the composition of the total preference value, it could be seen that economic, ecological and social interests had to be fulfilled by an alternative to achieve a good ranking.

The representatives of all stakeholder groups agreed that a restriction on water access is necessary to obtain sustainable aquifer management. The impediment of a further increase in the water demand by legal instruments was fundamental for a high ranking of an alternative. It can be reasoned that any other measures will be declined if there is no restriction on water access. Such measures are the reduction in the irrigated agricultural area, the reduction in the water allotment in drought periods, restrictions for high water needing crops, the improvement in extraction controls and the improvement in the irrigation efficiency. Alternatives 1-9 do not include such measures to limit the water access, and received consequently a low ranking. Also, the compliance of the ecological objectives relied mainly on this restriction.

Groundwater substitution by surface water was evaluated as an appropriate measure, although the preferred implementation factor differed among the stakeholders. Especially the 
high costs and the long realisation time of a full implementation impacted negatively on the results of environmental organisations and rural development. To agricultural representatives, it represented a necessary measure to guarantee water supply and economic activity.

Regarding the economic instruments, fertiliser taxation is considered the most adequate solution, especially because of its positive influence on the nitrate concentration in groundwater. However, the influence of water taxation on the results is quite low, and is considered less adequate than other measures.

In general, it can be observed that the main question considered a good alternative is not only "what is the best measure", but also "what is the implementation stage of a measure" and "how is the combination with other measures".

\subsection{Conflict potential}

A conflict potential might arise when there is a large variation in the ranking of certain alternatives across all the stakeholder groups. Analysing the conflict potential helps to focus on the proper measures for reaching a consensus solution. The conflict potential expressed by the mean deviation of the evaluation of alternatives by the stakeholders is shown in Fig. 7.

Analysing the fundamental actions, conflict potential could be found in the full implementation of the planned measures. High implementation stages of measures are just accepted by all stakeholder groups if they are combined with other fundamental measures. For instance, the option of full implementation of groundwater substitution is assigned a low ranking by ecologists unless the option also includes water use restrictions to prevent an overall increase in irrigation. On the other hand, agricultural representatives would accept a water use restriction provided that groundwater substitution measures are also implemented to avoid economic drawbacks.

The acceptance of economic measures varies significantly and has high conflict potential. According to the results, water taxes are not decisive for a good alternative ranking. Fertiliser taxes contain high conflict potential, but they are provided in the best-ranked alternatives, due to their regulation capacity of nitrate concentration in groundwater. However, in reality, the acceptance of taxes, especially by agricultural representatives (obtained by direct interviews), might be low, because of the economic losses as a consequence.

Uncertainties in the future by dynamic variables (scenario 2) are another source of conflicts. This might be because of the uncertainty of future development. Static external variables (scenario 1) provide more precise results, but they might not represent the future reality.

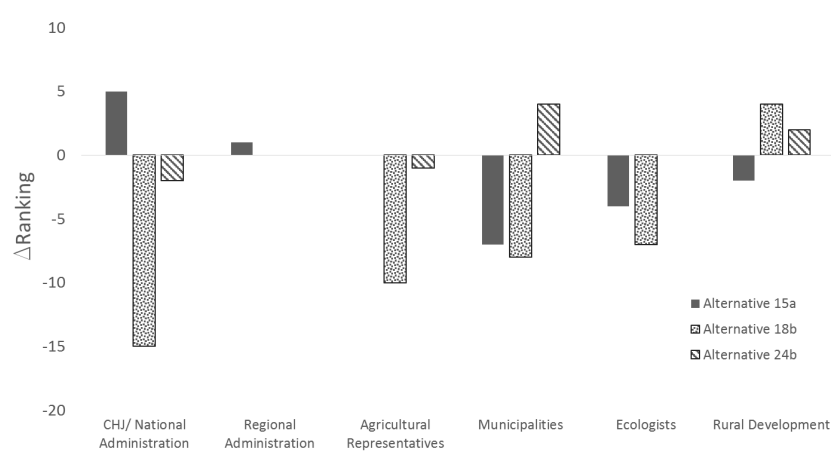

Figure 8. Change in ranking between scenario 1 and scenario 2 of the three best evaluated alternatives in scenario 1 .

\subsection{Scenario comparison}

The scenario comparison served to show up conflict points coming up because of uncertainties in variables in the future. In scenario 2, due to the inclusion of a greater urban water demand and climate change, the achievement of the objective of sustainable aquifer management was more difficult than in scenario 1. Figure 8 shows changes in ranking for the three best evaluated scenarios 1 . The main questions were whether there were significant changes in the preferences of outcomes and how the alternatives change between the two scenarios.

Looking at the best evaluated alternatives in both scenarios, it could be seen that the most preferred alternatives are not entirely the same, but that the focal points of wellevaluated alternatives were rather similar. The following similarities could be detected.

- Alternatives with the focus on just one measure are evaluated worse than those with several different measures of the fundamental actions.

- To obtain a good ranking, a restriction on the water access has to be implemented.

- A substitution of groundwater by surface water on a medium level of implementation is recommended.

- Control of nitrate contamination by fertiliser taxation is desired to fulfil the ecological objectives of the WFD.

Focusing on the differences between the scenarios, the following shifts could be observed.

- Alternatives with a combination of various fundamental actions on a medium level of implementation show up with the highest losses (although their absolute rank can still be high).

- The highest improvement in alternative ranks can be observed in the alternatives with more rigorous measures as a consequence of the higher necessity of actuating, due to the bigger water resource availability problem. 
Table 3. Results of sensitivity analysis: influence of changes in attribute levels on the preference value for all stakeholder groups in $\%$ relative to the total value.

\begin{tabular}{lrrrrr}
\hline & \multicolumn{5}{c}{ Positive variation of attribute levels } \\
\hline$(\%)$ & $15 \mathrm{a}$ & $15 \mathrm{~b}$ & $18 \mathrm{a}$ & $18 \mathrm{~b}$ & $24 \mathrm{~b}$ \\
\hline Max. variation & 13.9 & 12.4 & 18.2 & 17.6 & 13 \\
Min. variation & -7.5 & -7.7 & -9.9 & -9.6 & -10.5 \\
Average variation & 1.7 & 1.4 & 1.2 & 1.3 & 1.3 \\
\hline \multicolumn{5}{c}{ Negative variation of attribute levels } \\
\hline$(\%)$ & $15 \mathrm{a}$ & $15 \mathrm{~b}$ & $18 \mathrm{a}$ & $18 \mathrm{~b}$ & $24 \mathrm{~b}$ \\
\hline Max. variation & 3.2 & 1.2 & 11 & 10.7 & 8.4 \\
Min. variation & -17.2 & -16.2 & -22.9 & -20 & -19 \\
Average variation & -5 & -5.3 & -3.6 & -3.3 & -3.8 \\
\hline
\end{tabular}

- Also, the status quo alternative improves the acceptance. This might be because of the decreased cost efficiency of the measures. In other words, the cost of measures is not justified by the result.

Differences between the scenarios could be detected, but nevertheless the tendencies of the best-ranked alternatives were the same, and alternatives with a mix of different measures were the best ranked in both scenarios. Nevertheless, in the MO case, the differences in the preferences of outcomes between the scenarios were of moderate importance.

\subsection{Sensitivity analysis}

The sensitivity analysis was applied to test the robustness of the results towards uncertainties in the inputs. The results of the MAVT depend on two principle input factors:

- the attribute levels of the alternatives (consequence matrix); and

- the evaluation of the attributes by the stakeholders.

The uncertainty in attribute levels in consequence is expressed by a possible variation in the forecasted attribute levels for every alternative. The sensitivity analysis was realised by varying the attributes separately in the possible fluctuation range and analysing the influence on the outcome of the alternatives. The fluctuations arise from uncertainties in the underlying models of attributes (e.g. the groundwater model of the Júcar River basin, Sahuquillo et al., 2008), but also from expert rated uncertainty ranges in qualitatively evaluated attributes. The attributes high irrigated area, low implementation costs, and maintenance and management costs are excluded from the sensitivity analysis. They include fundamental characteristics defining the consequences of the alternatives, and are consequently treated as fixed values. The robustness of the preferences of the alternative varies within the stakeholder groups. Despite the influence on the preference value, the effect on the total ranking is quite low, and the

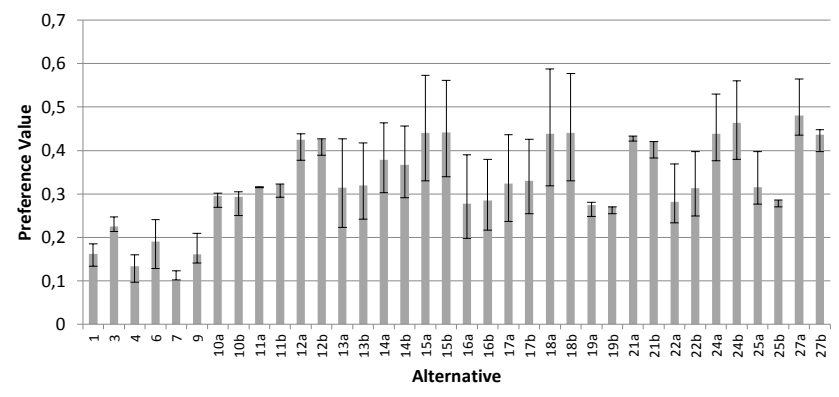

Figure 9. Preference values of stakeholder group "Ecologists" (bars) and fluctuation range due to different valuations of attributes within the stakeholder group.

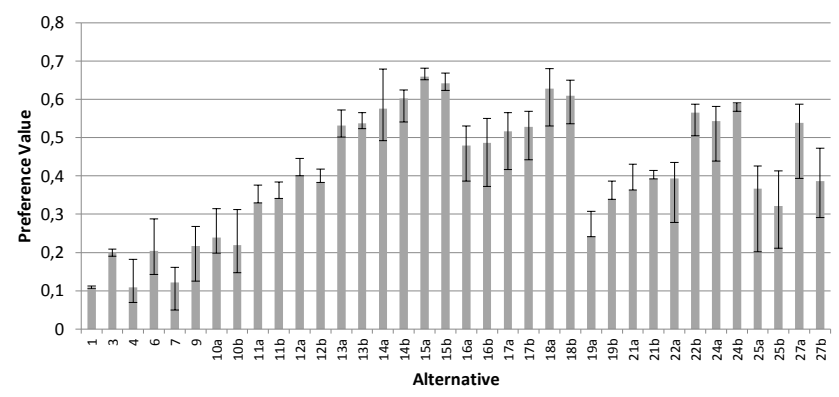

Figure 10. Preference values of stakeholder group "Municipalities" (bars) and fluctuation range due to different valuations of attributes within the stakeholder group.

basic structure of the ranking does not change (Table 3 ). The most preferred alternatives also obtain a high ranking, considering the uncertainty range. Referring to the uncertainties in the attribute levels, no significant negative variations are observable.

The uncertainty in the valuation of the attributes is given by different value functions and weights assigned by different representatives within one stakeholder group, which results in different preference values and alternative rankings. A similar valuation within a stakeholder group creates homogeneity and uncertainty becomes low. The sensitivity analysis for uncertainty in valuations was done for stakeholder groups with more than one representative. Uncertainties within the stakeholder groups were significant for environmental organisations (Fig. 9); meanwhile, municipalities (Fig. 10) and rural development had quite similar evaluations. This was interesting, as one would expect a lower discrepancy between ecologists than between other stakeholder groups.

\subsection{Discussion and conclusions}

Finding the optimal solution with the multi-attribute value theory in water resource problems seems to be difficult, requiring that complex structures be reduced to one value, expressing the acceptance or negotiation of an alternative. 


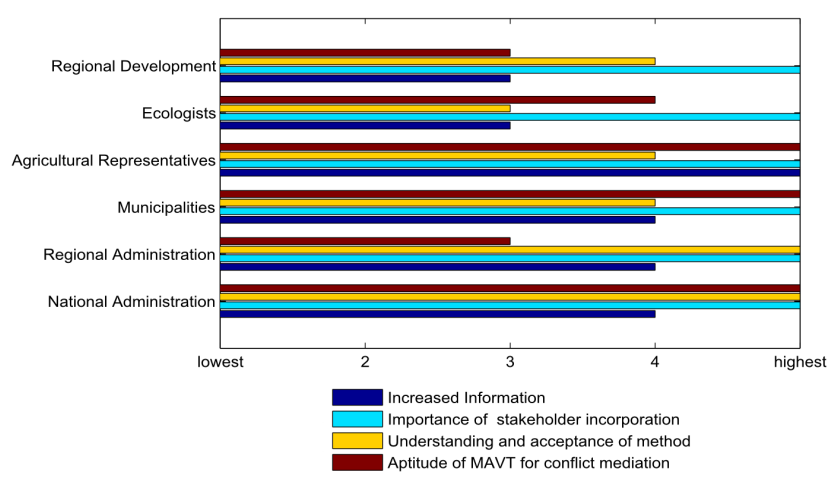

Figure 11. Average evaluation of the method based on stakeholders' feedback.

More complex methods like for instance ELECTRE (San Cristóbal, 2012) might be more appropriate for finding the best solution, but in the application of these there is a risk of non-transparency and a lack of understanding about the method among the participating stakeholders.

Nevertheless, the applied decision analysis framework based on the MAVT is a useful method for finding possible conflict points between the multiple stakeholders, helping also to identify possible consensus solutions. Furthermore, it is possible to define basic criteria for alternative planning, to guarantee a high acceptance of measures and to avoid future conflicts.

The acceptance of the method is quite high (see Fig. 11) because of its simplicity (see also Marttunen et al., 2013). The involvement of stakeholders at the beginning of the planning process, especially in the setting of the objectives, is considered important for obtaining high acceptance. It is important to weigh the necessary complexity of the model with the comprehensibility. Stakeholders have to be chosen carefully in terms of their knowledge of the issue, and they should have a good overview of the problem. If not, the valuations will be made without basing them on facts. If stakeholders understand the method, the acceptance of the results will be higher, and their contribution to conflict resolution too, since the results become more acceptable.

The holistically assessed preferences given by some stakeholders are mostly coherent with the results of the MAVT method. In comparison to a holistic ranking of options, the MAVT method has the advantage of creating a more detailed evaluation framework, which enables a more informative analysis to be undertaken. This includes a more detailed analysis of conflict potential and the ability to undertake uncertainty and sensitivity analysis.

The approach has been applied to the analysis of sustainable management of the MO aquifer, allowing one to elicit stakeholder groups' values and to evaluate groundwater management options. Stakeholders clearly preferred combined measures for economic reasons, and cause smaller impacts, because impacts are distributed in various sectors. For an al- ternative to be considered good in $\mathrm{MO}$, ecologic, economic and also social interests have to be considered. Logically, among the different stakeholder groups, the focus differs, but the best-ranked alternatives are still the same due to their basic structure. The representatives of all stakeholder groups agree that a restriction on water access is necessary to obtain sustainable aquifer management. Other measures just have efficiency if there is no additional increase in the water use. Also, the compliance of the ecological objectives relies mainly on this restriction. Groundwater substitution by surface water is evaluated as an appropriate measure, although the preferred implementation factor can differ among the stakeholders. Especially the high costs and the long realisation time of a full implementation affect negatively the results of environmental organisations and rural development. To agricultural representatives, groundwater substitution represents a necessary measure to guarantee water supply and economic activity. According to economic instruments, fertiliser taxation is considered the most adequate solution to achieve a good ecological status, especially because of its ability to limit the concentration of nitrate in the groundwater. The influence of water taxation on the results however is quite low and is considered less adequate than other measures.

Although the number of alternatives seemed to be unmanageable for the stakeholders at the beginning, the MAVT approach helped them to get more sensitised to the complexity of groundwater management in this aquifer and to elicit stakeholders' preferences and potential conflict points. In summary, the applied MAVT method is a useful support tool for planning processes; not for finding the best solution, but for avoiding future conflicts and finding potential consensus solutions by a detailed analysis of the measure rank based on the stakeholder preferences and values. Also, it serves to sensitise stakeholders to competing interests in environmental problems.

Acknowledgements. The authors would like to thank all stakeholders for the cooperation and participation in this study. We extend special thanks to Alfonso Calera of the IDR (Instituto de Desarollo Regional) of the University of Castilla-La Mancha for the organisation of the workshop with the stakeholders to introduce the study, as well as to the Jucar River Basin Agency (Confederacion Hidrografica del Júcar), represented in the meeting by Luis Garijo, and the Junta Central de Regantes de la Mancha Oriental (represented by its president, Francisco Belmonte) for all the data and information provided. This work has been partially funded by the European Community 7th Framework GENESIS project (no. 226536) on groundwater systems and the Plan Nacional de I+D+I 2008-2011 of the Spanish Ministry of Science and Innovation (projects CGL2009-13238-C02-01 and CGL200913238-C02-02 on climate change impacts and adaptation).

Edited by: A. Allan 


\section{References}

Belton, V. and Stewart, T. J.: Multiple Criteria Decision Analysis. An Integrated Approach, Springer US, Boston, MA, 2002.

Bogardi, J. J. and Nachtnebel, H. P.: Multicriteria decision analysis in water resources management, UNESCO, Paris, 1994.

Bogardi, J. J., Nachtnebel, H. P., and Duckstein, L.: Multicriterion Analysis for Regional Water Resource Development, Part I: Cost Effectiveness Approach, Environ. Syst. Anal. Manage., 74-81, 1982.

Bromley, J., Cruces, J., Acreman, M., Martinez, L., and Llamas, M. R.: Problems of sustainable groundwater management in an area of over-exploitation: the Upper Guadiana catchment, central Spain, Int. J. Water Resour. Develop., 17, 379-396, 2001.

Castaño, S., Sanz, D., and Gómez-Alday, J. J.: Methodology for quantifying groundwater abstractions for agricultura via remote sensing and GIS, Water Resour. Manage., 24, 795-814, 2010.

Chirivella-Osma, V.: Tesis doctoral: Caracterización de los futuros escenarios climáticos en la Comunidad Valenciana: propuestas de mejora para la evolución de la oferta y demanda de recursos hídricos, Universidad Politécnica de Valencia, Valencia, Spain, 2010 (in Spanish).

Chirivella-Osma, V., Capilla Romá, J. E., and Pérez Martín, M. A.: Modelling regional impacts of climate change on water resources: the Júcar basin, Spain, Hydrol. Sci. J., 60, 30-49, 2015.

CHJ: Esquema provisional de Temas Importantes, Ministerio de Medio Ambiente y Medio Rural y Marino. Confederación Hidrográfica del Júcar, Spain, 2009 (in Spanish).

Martín de Santa Olalla Mañas, F., Brasa Ramos, A., Fabeiro Cortes, C., Fernándo González, D., and López Córcoles, H.: Improvement of irrigation management towards the sustainable use of groundwater in Castilla-La Mancha, Spain, Agr. Water Manage., 40, 195-205, 1999.

European Commission: Directive 2000/60/EC establishing a framework for Community action in the field of water policy, EUWFD, 2000.

Foster, S., Garduño, H., Kemper, K., Tuinhof, A., Nanni, M., and Dumars, C.: Sustainable Groundwater Management, Conept \& Tools. Groundwater Quality Protection. Defining strategy and setting priorities. GW Mate Briefing Notes Series 2002 (Note 8), available at: www.worldbank.org/gwmate, 2002.

Hostmann, M.: Decision support for river rehabilitation, ETH, Zürich, 2005.

Hostmann, M., Bernauer, T., Mosler, H.-J., Reichert, P., and Truffer, B.: Multi-attribute value theory as a framework for conflict resolution in river rehabilitation, J. Multi-Crit. Decis. Anal., 13, 91-102, 2005.

Kangas, A., Kangas, J., and Kurttila, M.: Decision support for forest management, Springer, Berlin, 2008.

Karjalainen, T. P., Rossi, P. M., Ala-aho, P., Eskelinen, R., Reinikainen, K., Kløve, B., Pulido-Velazquez, M., and Yang, H.: A decision analysis framework for stakeholder involvement and learning in groundwater management, Hydrol. Earth Syst. Sci., 17, 5141-5153, doi:10.5194/hess-17-5141-2013, 2013.

Keeney, R. L. and Raiffa, H.: Decisions with multiple objectives. Preferences and value tradeoffs, Wiley, New York NY u.a., 1976.

Llamas, M. R. and Martínez-Santos, P.: Intensive groundwater use: silent revolution and potential source of social conflicts, J. Water Resour. Plann. Manage., 131, 337-341, 2005.
López Fuster, P.: Los regadíos en la Mancha Oriental, Albacete, 1999.

López Sanz, G.: Estudios de fuentes, manantiales y pequeños espacios del agua n la cuenca media de los ríos Júcar y Cabriel, 2010.

Lopez-Gunn, E.: The Role of Collective Action in Water Governance: A Comparative Study of Groundwater User Associations in La Mancha Aquifers in Spain, Water Int., 28, 367-378, 2003.

Lopez-Gunn, E. and Matinez-Cortina, L. M.: Is self-regulation a myth? Case study on Spanish groundwater user associations and the role of higher-level authorities, Hydrogeol. J., 14, 361-379, 2006.

Marttunen, M. and Hämäläinen, R. P.: Decision analysis interviews in environmental impact assessment, Eur. J. Oper. Res. 87, 551$563,1995$.

Marttunen, M., Mustajoki, J., Dufva, M., and Karjalainen, T. P.: How to design and realize participation of stakeholders in MCDA processes? A framework for selecting an appropriate approach, EURO J. Decis. Process., 1-28, doi:10.1007/s40070-013-00163, 2013.

Moratalla, A., Gomez Alday, J., De las Heras, J., Sanz, D., and Castaño, S.: Nitrate in the water-supply wells in the Mancha Oriental Hydrogeological System, Water Resour.Manage., 23, 1621$1640,2009$.

Mustajoki, J. and Hämäläinen, R. P.: Web-HIPRE: Global decision support by value tree and AHP analysis, INFOR, 38, 208-220, 2000.

Mustajoki, J., Saarikoski, H., Marttunen, M., Ahtikoski, A., Hallikainen, V., Helle, T.,Hyppönen, M., Jokinen, M., Naskali, A., Tuulentie, S., Varmola, M., Vatanen, E., Ylisirniö, A.-L.: Use of decision analysis interviews to support the sustainable use of the forests in Finnish Upper Lapland, J. Environ. Manage., 92, 15501563, doi:10.1016/j.jenvman.2011.01.007, 2011.

Peña-Haro, S., Llopis-Albert, C., Pulido-Velazquez, M., and PulidoVelazquez, D.: Fertilizer standards for controlling groundwater nitrate pollution from agriculture: El Salobral-Los Llanos case study, Spain, J. Hydrol., 392, 174-187, 2010.

Peña-Haro, S., García-Prats, A., and Pulido-Velazquez, M.: Influence of soil and climate heterogeneity on the performance of economic instruments for reducing nitrate leaching from agriculture, Sci. Total Environ., 499, 510-519, 2014.

Pöyhönen, M. and Hämäläinen, R.: On the convergence of multiattribute weighting methods, Eur. J. Operat. Res., 129, 569-585, doi:10.1016/S0377-2217(99)00467-1, 2001.

Roberts, R. and Goodwin, P.: Weight approximations in multiattribute decision models,J. Multi-Crit. Decis. Anal., 11, 291303, doi:10.1002/mcda.320, 2002.

Sahuquillo, A., Castaño, S., Cassiraga, E., Calera, A., GómezAlday, J. J., and Peña, S.: Modelo de flujo subterráneo de los acuíferos de la Mancha Oriental y sus relaciones con los ríos Júcar y Cabriel, Albacete, Valencia, UPVLC, UCLM, 2008.

San Cristóbal, M. and Ramón, J.: Multi criteria analysis in the renewable energy industry, London, New York: Springer (Green energy and technology), ISBN:9781447123460, 2012.

Sanz, D., Gómez-Alday, J. J., Castaño, S., Moratalla, A., de las Heras, J., and Martínez-Alfaro, P. E.: Hydrostratigraphic framework and hydrogeological behaviour of the Mancha Oriental System (SE Spain), Hydrogeol. J., 17, 1375-1391, 2009. 
Sanz, D., Castaño S., Cassiraga, E., Sahuquillo, A., Gómez-Alday, J. J., Pña, S., and Calera, A.: Modeling aquifer-river interactions under the influence of groundwater abstraction in the Mancha Oriental System (SE Spain), Hydrogeol. J., 19, 475-487, 2011.

Soncini-Sessa, R.: Integrated and participatory water resources management-practice, Vol. 1b, Elsevier, Amsterdam, 2007.
Stefanopoulos, K., Yang, H., Gemitzi, A., and Tsagarakis, K. P.: Application of the Multi-Attribute Value Theory for engaging stakeholders in groundwater protection in the Vosvozis catchment in Greece, Sci. Total Environ., 470-471, 26-33, doi:10.1016/j.scitotenv.2013.09.008, 2014.

von Winterfeldt, D. and Edwards, W.: Decision analysis and behavioural research, Cambridge Univ. Press, Cambridge u.a., 1986. 